\title{
Formation of the tefroid deposits in modern Kamchatka volcanic structures
}

\begin{abstract}
The article considers tefroids - a kind of volcanic-sedimentary formations that occur during the eruption as a result of displacement and washing of the erupted volcanicclastic material. Modern studies in Kamchatka and the Kuril Islands have made it possible to prove not only the synchronism of tefroid material with volcanism, but also its vast distribution, often predominating over volcanoterrigenic. Currently, in all the formations studied in detail in volcanic regions, the wide development of tefroids has been established. In terms of age, they are developed from the Early Precambrian and are formed in our time. As an example, the processes of formation of volcaniclastic formations in modern large Kamchatka volcano Bezymianny are considered. Various volcano-clastic material lies on the slopes of these volcano: deposits of pyroclastic flows, block material of lava flows and extrusive eruptions and other genetic types of volcanics. The most diverse forms of extrusive structures in the process of decompression of the material of their eruptions are involved in the formation of tefroid deposits. On the slopes of volcano and in the area of development of dry watercourses, there is a constant movement of clastic material to the foot of volcanoes. This diverse material is sorted by size, rolled around and forms wellseasoned tefroid interlayers.
\end{abstract}

Keywords: kamchatka, volcano bezymianny, tefroids, extrusion, decompression pyroclastic, eruption
Volume 4 Issue I - 2020

PK Skuf'in
Geological Institute, Kola Science Centre, Russia

Correspondence: PK Skuf'in, Geological Institute, Kola Science Centre, RAS, Apatity, Russia, Email sku@geoksc.apatity.ru

Received: December 12, 2019 | Published: February 03, 2020

\section{Introduction}

During the eruption of volcanoes in modern and ancient volcanic regions, among the deposits of volcano-sedimentary rocks, a special place is occupied by the so-called tefroid rocks (tefroids), which are synchronous to the eruption formations, consisting of partially rounded and sorted pyroclastics, often mixed with terrigenous material. Tefroid deposits differ from the volcano-terrigenous rocks, which also consist of rounded and sorted volcanic fragments, but formed due to the destruction of volcanic rocks that are not synchronous with the eruption. In tefroids, volcaniclastic material is partially represented by rounded and semi-rounded fragments of volcanic glass, while in tuffit deposits volcanic glass undergoes decomposition. ${ }^{1}$ Fragments of volcanic glass fall into the composition of tefroid deposits during synvolcanic emissions of pyroclastic material and during the destruction of extrusive volcanic structures. Before tefroids, they did not stand out from the group of volcano-sedimentary rocks, since there was no data on the conditions and speed of their formation. It was believed that they are not synchronous with the manifestation of volcanism and are formed after the termination of eruptions due to lithified volcanics. Initially, tefroids included rocks formed only by rounded and sorted tefra. Subsequently, any rounded and sorted volcanic-clastic material began to be referred to as tefroids: block boulders of lava flows, clastic material of extrusive massifs and individual extrusive obelisks, tefra of pyroclastic flows and other products of eruptions. Modern studies in Kamchatka and the Kuril Islands have made it possible to prove not only the synchronism of tefroid material with volcanism, but also its vast distribution, often predominating over volcanoterrigenic. ${ }^{2}$ Currently, in all the formations studied in detail in the Far East, Siberia, the Urals, the Caucasus and other volcanic regions, the wide development of tefroids has been established. In terms of age, they are developed from the Early Precambrian and are formed in our time.

Tefroids, like all volcano-sedimentary rocks, are subdivided according to the degree of rounding of the fragments, by the size of the clastic material, and also by the degree of lithification, when loose varieties (from block tefroids to pelites) and lithified (from tefroidconglomerates to mudstones) are distinguished. ${ }^{1}$ When studying these rocks, loose pyroclast-tefroid rocks are isolated (admixture of pyroclastic material - up to $50 \%$ ); accordingly, when determining, according to the size of the debris, a name is given with a defining adjective: pyroclast-tefroid boulder rock, pyroclast-tefroid gravel, pyroclast-tefroid sand, etc., and for lithified varieties - pyroclasttefroid conglomerate, pyroclast-tefroid gravelite, pyroclast-tefroid sandstone. Terrigenous-tefroid loose sediments (admixture of terrigenous material - up to $50 \%$ ) is given the name: terrigenoustefroid boulder rock, terrigenous-tefroid gravel, terrigenous-tefroid sand, etc. Accordingly, lithified species are called: terrigenoustefroid conglomerate, terrigenous tefroid gravel, terrigenous tefroid sandstone. Pelitic tefroids are usually not investigated by volcanologists, since pyroclastic fragments smaller than $0.01 \mathrm{~mm}$ are not amenable to diagnosis.

Due to the fact that tefroids belong to volcano-sedimentary rocks, their textures and structures are more comparable with purely sedimentary counterparts. The textures of tephroids are predominantly layered, the lamination can be thin, from centimeters, and coarse, measured by meters, and the high formation rates of tefroids contribute to the formation of coarser layering. Within powerful layers, the tefroids texture is massive, dense. The structure is often uniformly 
granular, less often porphyritic. The latter, as a rule, is formed in volcanoclastic tefroids. For the pyro- and vucanoclastic tefroids, the vitrophyric structure of the clastic material is characteristic. This is due to the rapid cooling of the ashes during the eruption and is one of the hallmarks of tefroids from volcanoterrigenous rocks. Tefroids cement is formed by the decomposition of fine ash material and is usually represented by aqueous aluminosilicates (montmorillonite, beidellite, etc.), with a large amount of opal, due to which durable cements are formed. Tefroids are characterized by the absence of clay interlayers. In volcanoterrigenous rocks, on the contrary, there is a large amount of clay material.

A typical example of the formation of pyroclastic tefroids is their formation during the eruption of the Japanese volcano Taketomi in $1972 .^{2}$ A side eruption within 1 month yielded 100 million $\mathrm{m}^{3}$ of pyroclastic, which partially fell on the shore of the Ochotskoye Sea, forming a 5-meter thick layer of tefroid near the cone, gradually thinning along as removed. As a result of the destruction of the slag cone of this eruption over $40 y e a r s$, about $30 \%$ of the original loose material remained in place. The washed-out volcaniclastic formed a tefroid horizon with a thickness of $70 \mathrm{~m}$ along the shore. It is characteristic that the degree of rounding of tephroids is approximately the same both in terms of thickness of the tephroid horizons and in the area of their development. At the same time, rolling around of moving tephroids occurs throughout the year. In the formed tefroids, the pyroclastic material is sorted by size and rounded, the fragments are semi-angular and semi-rounded, less often well rounded. The dimension of loose tefroid is gravel and psammite, aleuritic material is small, and the pelitic is completely washed.

Volcanoclastic tephroids are also significantly developed in large stratovolcanoes Klyuchi and Avacha, far from the coastline. Various volcano-clastic material lies on the slopes of these volcanoes: deposits of pyroclastic flows, block material of lava flows and extrusive eruptions and other genetic types of volcanics. On the slopes of volcanoes and in the area of development of dry rivers and watercourses, there is a constant movement of clastic material to the foot of volcanoes. This diverse material is sorted by size, rolled around and forms well-seasoned tefroid interlayers. The young volcanoes Klyuchi and Avacha are 10,000years old. During this time, on the periphery of volcanoes in the form of a plume of $10-15 \mathrm{~km}$ wide, tefroid strata with a thickness of more than $100 \mathrm{~m}$ were formed.

The real creation of nature such as a master class is the active Bezymianny volcano in the Klyuchi group of volcanoes, which presents the researcher with a collection of forms of volcanic eruptions creating unique volcanic structures, upon destruction of which the thickness of tefroid deposits is formed.

Bezymianny volcano is an active stratovolcano on the East Mountain Range, near the Klyuchi volcano..$^{3-5}$ The time of formation is Holocene. The last eruption is 2017 . The absolute height is $2882 \mathrm{~m}$ (before 1956-3075m), the volcanic structure includes a young active stratovolcano and the remains of an old volcano destroyed by the 1956 eruption, on the site of which a crater measuring $1.3 \times 2.8 \mathrm{~km}$ formed. At the foot of the volcano there are 16large extrusive structures (extrusive domes, large obelisks, etc.).

In the extrusive type of eruption, lava, which is in a viscous or already solidified state, is extruded to the surface. ${ }^{1}$ Volcanic rocks of extrusive facies are usually located in the upper parts of volcanic apparatus, filling the vents of volcanoes, as well as ring and conical dikes. They are usually represented by lavas of a rhyolite-andesite composition with a massive, and sometimes well-defined fluid or banded texture, oriented in the direction of lava movement. The shape of the extrusive bodies depends on the shape of the volcanic channel through which they are extruded. They form domes, obelisks, an irregular body shape. Lava extrusion has a loose texture and crumbles with a light impact of a geological hammer. Therefore, extrusive eruptions are usually accompanied by geologically instantaneous formation of fields and covers of lavoclastic rocks, which, when moving down the slopes of volcanoes, turn into lavo-clastic flows and later into tefroid deposits.

Eruption 1955-1956 was the first in the area since 1697 and, according to tephrochronological studies, occurred after a 1000year rest period. ${ }^{3,6}$ Before the eruption, the volcano had the shape of a regular cone $3085 \mathrm{~m}$ high (andesitic stratovolcano complicated by secondary extrusive domes). The eruption began on October 22, 1955 after a 23-day swarm of earthquakes. Until March 30, 1956, the eruption was moderate,"volcanic" in nature (pre-culminating stage).

At the top of the volcano, a crater with a diameter of $800 \mathrm{~m}$ formed, from which frequent ash emissions occurred up to a height of $7 \mathrm{~km}$. In November, the squeezing of a powerful dome of viscous lava began in the crater. This caused a strong (more than $100 \mathrm{~m}$ ) "protrusion" of the eastern slope of the volcano. The slope finally collapsed, and on March 30, 1956, a world-wide event began - a catastrophic eruption (culmination stage). Immediately after the collapse, a colossal "directed explosion" followed, caused by the huge pressure of the extruding lava penetrating.

The material ejected by the explosion caused a "pyroclastic wave" (a turbulent flow of a hot mixture of gas and pyroclastics). Its speed exceeded $60 \mathrm{~m} / \mathrm{s}$, the temperature was about $300^{\circ} \mathrm{C}$. After a directed explosion, pyroclastic streams up to $30 \mathrm{~km}$ long descended along the slope. The height of the eruptive eruption cloud reached a height of about $35 \mathrm{~km}$. The explosion at the volcano resulted in a horseshoe-shaped crater with a diameter of $\sim 1.3 \mathrm{~km}$. A cover of specific pyroclastic deposits (deposits of "directed explosion") arose on the eastern slope. After paroxysm (the post-culminating stage), the dome of viscous lava (Volcanic dome Novy (New)) continued to be squeezed in the crater, the formation of which continues to this day (Figures 1).

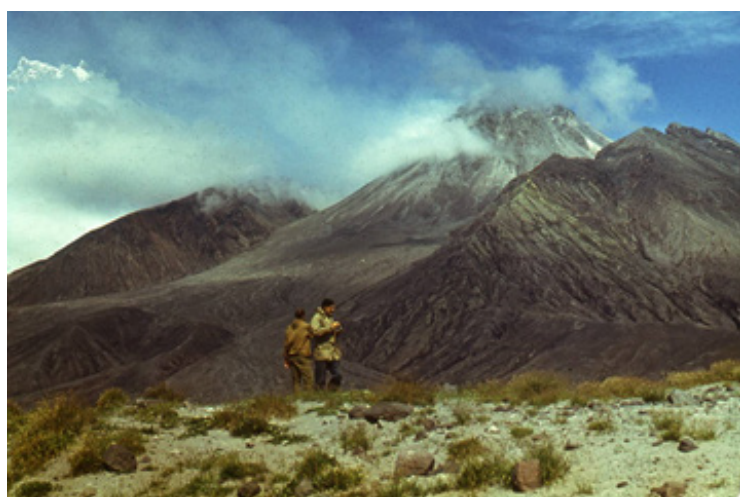

Figure I Volcano Bezymianny - eastern slope. Above the emerging Volcanic Dome Novy, rising clouds of gas are visible. The foot of this dome is covered with the latest deposits of volcaniclastic material.

In the early years, the Novy Dome was continuously squeezed out of hard obelisks. In the future, the growth of the dome became intermittent, and along with rigid blocks since 1977, viscous extrusions began to be squeezed. Currently, extrusions cover the entire surface of the dome, which almost filled the crater of 1956. 
The dome formation is accompanied by weak and moderate explosive eruptions (1-2per year), with the deposition of small blockyash pyroclastic flows up to $12 \mathrm{~km}$ long and associated pyroclastic clouds ashes. In recent years, during the eruptions, large collapses of the old parts of the dome began to occur. The catastrophic eruption of the volcano on March 30, 1956 became famous and was singled out by volcanologists as an independent type of eruption - "directed explosion" or "Bezymianny type", which is recognized by world volcanology ("directed blast", "lateral blast", "type Bezymianny").

In 1977 , as part of the Kamchatka volcanological detachment, I managed to work out the entire summer expedition season at Volcano Bezymianny. The volcano was in an active phase of activity. The Volcanic dome Novy formation continued, powerful pyroclastic flows constantly rolled along its slopes, often small-scale eruption occurred up to $0.5 \mathrm{~km}$ from the extrusive dome of block material and large blocks several $\mathrm{m}^{3}$ in size (Figures 2).

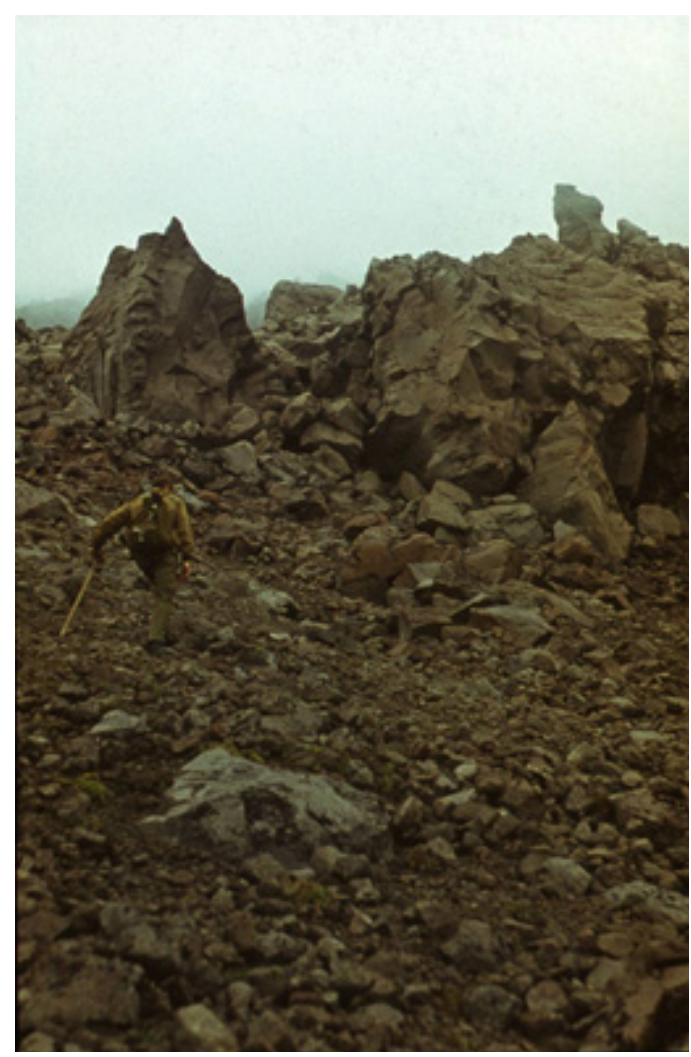

Figure 2 Large blocks of extrusive lava and coarse-clastic material ejected during local explosions at volcanic Dome Novy.

Smaller extrusion domes constantly formed at the foot of the volcano. At the same time, rather large domes after their appearance periodically continued active volcanic activity, up to the final formation of their morphological appearance. Observations in the areas of recent volcanism indicate the extreme transience of the processes of formation of volcanic extrusive structures, the discrete nature of their manifestation, and rapid destruction during weathering.

A typical example is the large young extrusive dome of Lohmaty. The uneven surface of the dome, the presence of numerous blocks and obelisks of different sizes gives the impression of a modern eruption with an age of several months (Figure 3).

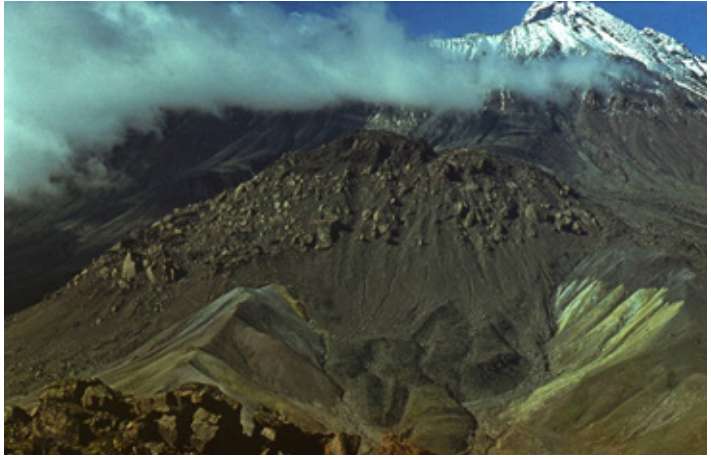

Figure 3 The young extrusive Dome of Lohmaty on the eastern slope of the volcano Bezymianny.

When studying the root zones of the andesitic extrusions of the Holocene volcanoes of Kamchatka, volcanologists When studying the root zones of the andesitic extrusions of the Holocene volcanoes of Kamchatka, volcanologists V. Sheimovich and M. Patoka found that "individual interstitial portions are vertical prismatic blocks of crystallized andesites, surrounded and separated by shelllayers of autoexplosive volcaniclastic rocks, which was caused by decompression of deep hard andesitic blocks under surface conditions". ${ }^{7}$ The thickness of such prisms varies between $5-100 \mathrm{~m}$. The authors write that thick layers of clastic material at the base of many Miocene-Pliocene volcanoes have the same "autoexplosive" origin, for which "it is hardly possible to assume a volcanic-terrigenous origin, since this material is located at the base of volcanoes, within their crater facies."

Our observations on Volcano Bezymianny confirm this data. In particular, it was possible to observe the forms of extrusion lava penetration also in the form of prismatic blocks of crystallized andesites (Figures 4).

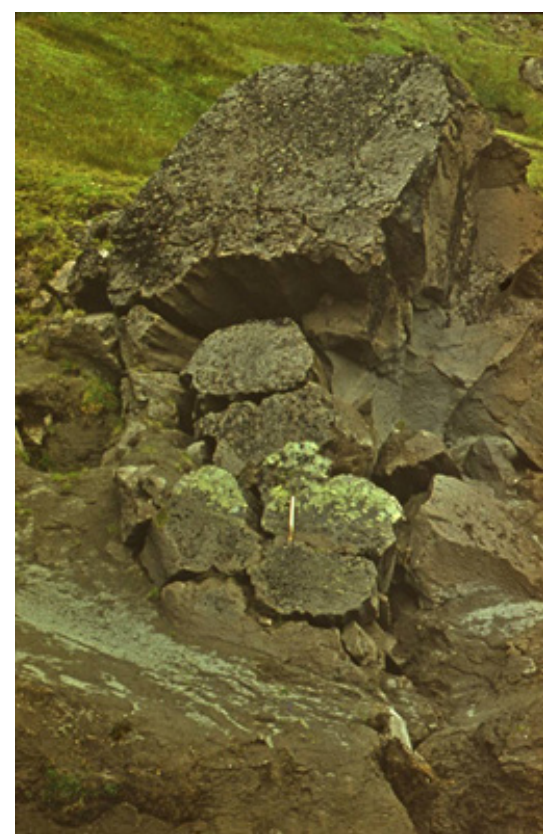

Figure 4 An example of an extrusive eruption in the form of a system of prismatic blocks. 
It can be stated that continuous (since 1956) eruptions of andesitic extrusive lavas, forming the Volcanic dome Novy, occurred in the form of protrusions of rigid blocks and were accompanied by explosions of different strengths and hot avalanches of andesitic lavas. The seemingly monolithic lumps of crystallized extrusive andesites, supplying material for these avalanches, literally crumbled in their hands into sand and gravel material, similar in size to the grains of minerals composing andesites. The Volcanic dome Novy and Volcano Bezymianny themselves stand as if immersed in this loose tefroid material, which is picked up by temporary streams, washed into deep ravines, many meters deep, and is carried away by the river system of the Suhaya Hapiza river (Figures 5-6).

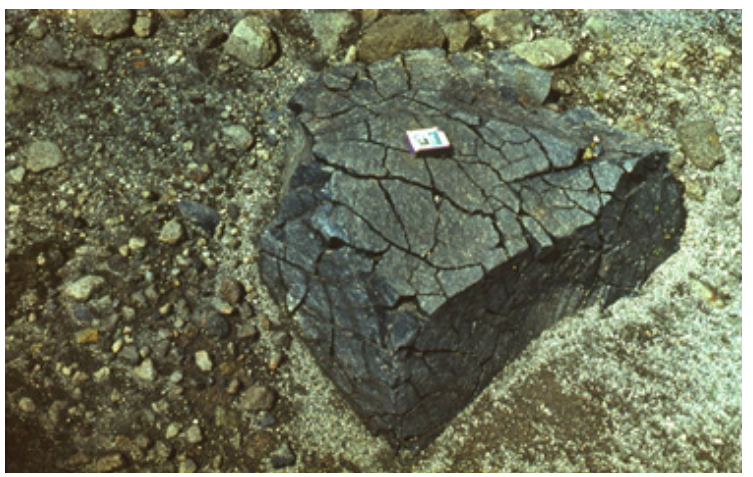

Figure 5 An extrusive lava block ejected over a distance of about $0.5 \mathrm{~km}$ during the formation of Dome Novy.Traces of decompression are visible.

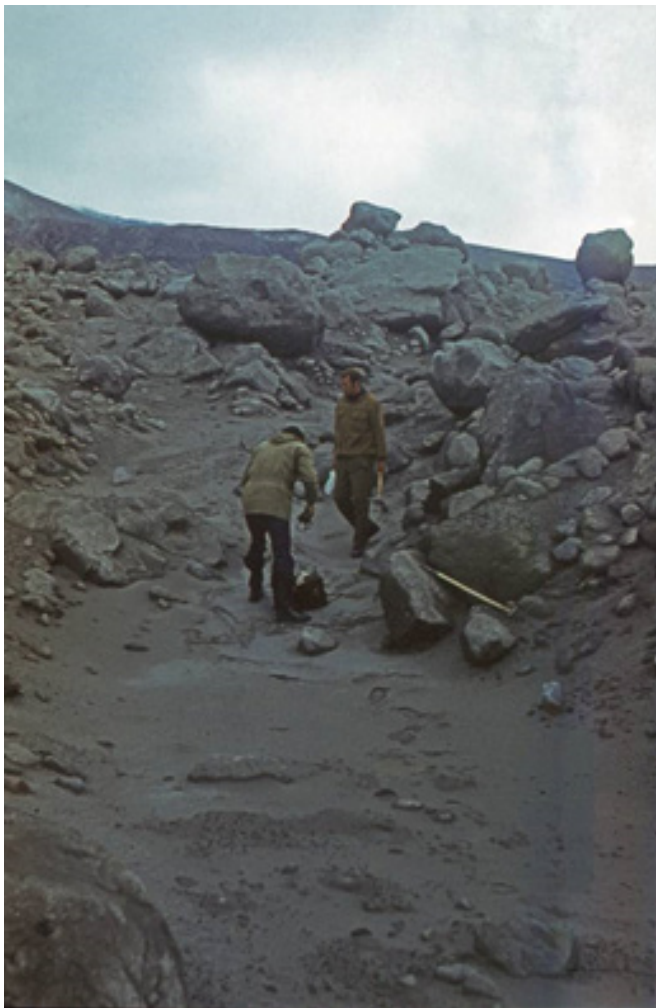

Figure 6 The formation of sand and gravel tefroid deposits during decompression of clastic material of extrusive emissions.

At the same time, at the foot of the Volcano Bezymianny one can observe examples of more ancient extrusive eruptions (Figures 7).

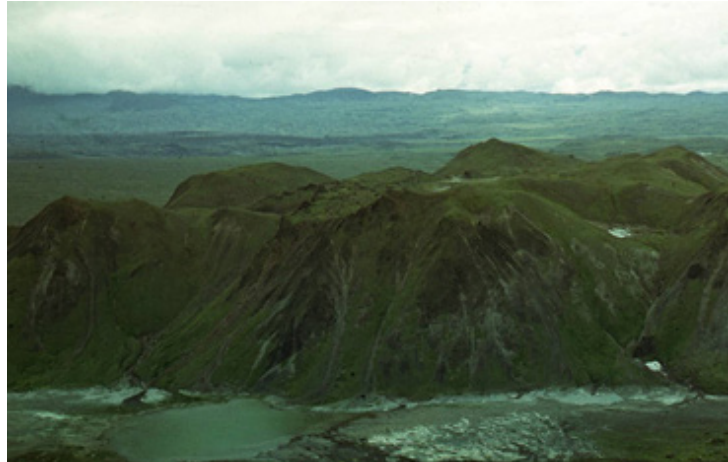

Figure 7 The ancient extrusive dome Plotina at the foot of the volcano Bezymianny. Over the years on the surface of extrusion soil cover was formed.

The infinitely inventive Nature enables us to observe a collection of bizarre volcanic structures. On the ancient volcanic dome at the foot of the volcano during its formation, a small extrusive dome of a smaller size with an ideal spherical shape was formed (Figure 8).

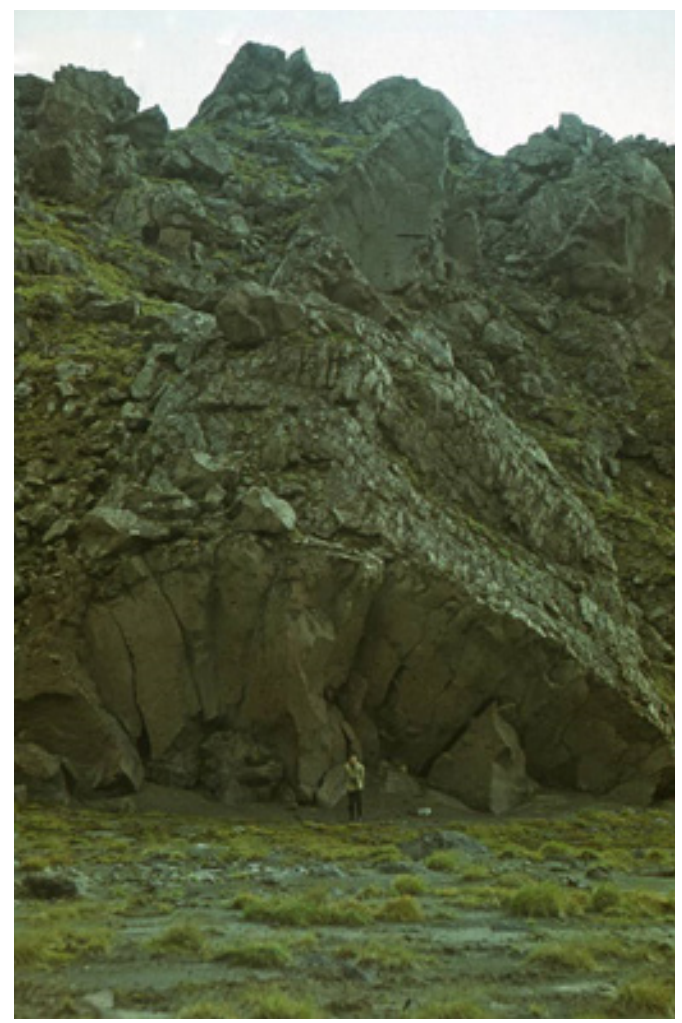

Figure 8 Extrusive dome of the correct spherical shape.

\section{Conclusion}

Summarizing the factual material cited, I would like to note that when I studied Volcano Bezymianny, I was, first of all, delighted with the magnificent and general panorama, and the individual views of this volcanic area. However, in addition to the beautiful views, any attentive observer will immediately be struck by the amazing variety of forms and features of the manifestation of volcanic activity on this volcano. Numerous examples of this diversity amaze the observer from the first stages of the study. Only a small part of this material, 
which usually eludes the attention of the venerable authors of monographs on volcanology, is given in the article.

In addition, it, however, only partially affects the most important problem of the formation of modern and fossilized tfroid deposits. Modern studies in Kamchatka, the Kuril Islands and other volcanic regions prove not only the synchronism of tefroid formations with volcanism, but also their huge distribution and frequent prevalence over volcanoterrigenous deposits. The materials cited in the article add certain facts that make it possible to additionally outline some details of this problem.

\section{Acknowledgments}

None.

\section{Conflicts of interest}

The authors declare that there is no conflict of interest.

\section{Funding}

None.

\section{References}

1. Maleev EF. Volcanoes (Reference). M Nedra; 1980. 270 p.

2. Girina OA. Pyroclastic deposits of andesitic volcanoes and the diagnosis of their genetic types. In the book. "Geodynamics and volcanism of the Kuril-Kamchatka island arc system". IVGiG FEB RAS, PetropavlovskKamchatsky. 2001;70-78.

3. Bogoyavlenskaya G Ye, Kirsanov IT. 25years of the volcanic activity of the Bezymianny volcano. Volcanology and seismology. 1981;2:3-13.

4. Vlodavets VI, Piip BI. Catalog of active volcanoes of Kamchatka. Bull volcanol station; 1957. p. 25.

5. Rudich KN. Stone torches of Kamchatka. Novosibirsk: Nauka; 1974. 176 p.

6. Belousov A, Voight B, Belousova M. Directed blasts and blast-currents: a comparison of the Bezymianny 1956, Mount St Helens 1980, and Soufriere Hills, Montserrat 1997 eruptions and deposits. Bulletin of Volcanology. 2007;69:801-840.

7. Sheimovich VS, Patoka MG. Feeding systems of volcanoes. Volcanology and Seismology. 1980;6:21-632. 